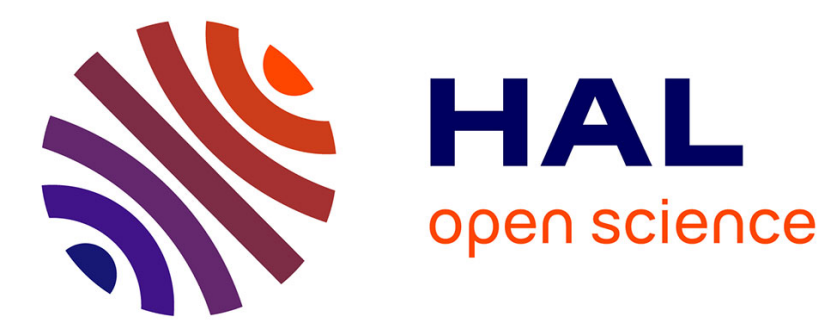

\title{
Exploring the source of short-term variations in respiratory data
}

\author{
Susanne Fuchs, Laura Koenig, Caterina Petrone
}

\section{To cite this version:}

Susanne Fuchs, Laura Koenig, Caterina Petrone. Exploring the source of short-term variations in respiratory data. Journal of the Acoustical Society of America, 2019, 145 (1), pp.EL66-EL71. 10.1121/1.5087272 . hal-02091229

\section{HAL Id: hal-02091229 \\ https://hal.science/hal-02091229}

Submitted on 5 Apr 2019

HAL is a multi-disciplinary open access archive for the deposit and dissemination of scientific research documents, whether they are published or not. The documents may come from teaching and research institutions in France or abroad, or from public or private research centers.
L'archive ouverte pluridisciplinaire HAL, est destinée au dépôt et à la diffusion de documents scientifiques de niveau recherche, publiés ou non, émanant des établissements d'enseignement et de recherche français ou étrangers, des laboratoires publics ou privés. 


\section{AUTHOR QUERY FORM}

\begin{tabular}{|l|l|l|}
\hline & Journal: J. Acoust. Soc. Am. & $\begin{array}{l}\text { Please provide your responses } \\
\text { and any corrections by } \\
\text { annotating this PDF and up- } \\
\text { Publishing }\end{array}$ \\
Article Number: 506901JAS & $\begin{array}{l}\text { loading it according to the } \\
\text { instructions provided in the } \\
\text { proof notification email. }\end{array}$ \\
\hline
\end{tabular}

\section{Dear Author,}

Below are the queries associated with your article; please answer all of these queries before sending the proof back to AIP. Please indicate the following:

Figures that are to appear as color online only (i.e., Figs. 1, 2,3)_ (this is a free service). Figures that are to appear as color online and color in print(a fee of $\$ 325$ per figure will apply).

Article checklist: In order to ensure greater accuracy, please check the following and make all necessary corrections before returning your proof.

1. Is the title of your article accurate and spelled correctly?

2. Please check affiliations including spelling, completeness, and correct linking to authors.

3. Did you remember to include acknowledgment of funding, if required, and is it accurate?

\begin{tabular}{|c|l|}
\hline $\begin{array}{c}\text { Location in } \\
\text { article }\end{array}$ & $\begin{array}{c}\text { Query / Remark: click on the Q link to navigate } \\
\text { to the appropriate spot in the proof. There, insert your comments as a PDF annotation. }\end{array}$ \\
\hline AQ1 & $\begin{array}{l}\text { Please check that the author names are in the proper order and spelled correctly. } \\
\text { Also, please ensure that each author's given and surnames have been correctly } \\
\text { identified (given names are highlighted in red and surnames appear in blue). } \\
\text { Please note journal style only permits one additional affiliation and it must be set as a } \\
\text { footnote. Please check changes made. } \\
\text { Please check change from "in the next section" to "in Sec. 1.1" to comply with journal } \\
\text { style. } \\
\text { AQ3 } \\
\text { AQ name of the manufacturer and their location must be provided for all equipment used } \\
\text { in this paper. } \\
\text { Please verify the definition of "SE." } \\
\text { AQ6 } \\
\text { Ladefoged and McKinney (1963) is not cited in text. Please cite where appropriate or } \\
\text { delete from the reference list. } \\
\text { Please provide the date this site was last viewed. } \\
\text { AQ8 } \\
\text { Please provide a digital object identifier (doi) for Ladefoged and Loeb (2002), Ladefoged } \\
\text { at } \\
\text { www.doi.org/. If a doi is not available, no other information is needed from you. }\end{array}$ \\
\hline
\end{tabular}

Thank you for your assistance. 


\title{
Exploring the source of short-term variations in respiratory data
}

AQ1AQ2

\author{
Susanne Fuchs ${ }^{\text {a) }}$ and Laura L. Koenig ${ }^{\text {b) }}$ \\ Leibniz-Centre General Linguistics (ZAS), Berlin, 10117, Germany \\ fuchs@leibniz-zas.de,koenig@haskins.yale.edu \\ Caterina Petrone \\ Aix-Marseille Université, CNRS, Laboratoire Parole et Langage, Aix-en-Provence, France \\ caterina.petrone@lpl-aix.fr
}

\begin{abstract}
This study explores short-term respiratory volume changes in German oral and nasal stops and discusses to what extent these changes may be explained by laryngeal-oral coordination. It is expected that respiratory volumes decrease more rapidly when the glottis and the vocal tract are open after the release of voiceless aspirated stops. Two experiments were performed using Inductance Plethysmography and acoustics, varying consonantal properties, loudness, and prosodic focus. Results show consistent differences in respiratory slopes between voiceless vs voiced and nasal stops, which are more extreme in a loud or focused position. Thus, respiratory changes can even occur at a local level.

(C) 2019 Acoustical Society of America [DDO'S]

Date Received: August 4, 2018

Date Accepted: December 29, 2018
\end{abstract}

\section{Introduction}

During speech production, chest wall displacements and subglottal pressures mainly show slow, long-term variations (e.g., Leanderson et al., 1987), but short-term changes in respiratory signals, i.e., brief excursions from the long-term baselines, have also been observed. As elaborated in Sec. 1.1, these short-term changes have most typically been associated with word or sentence stress (Ladefoged, 1968; Ohala, 1990), but a few authors have noted the possibility of segmental effects on respiratory measures, particularly in cases where both the glottis and upper vocal tract are open, leading to rapid venting of air. Data reporting on such segmental effects have been sparse and anecdotal, however, and it is not clear whether such results can consistently be observed across multiple speakers. This paper systematically assesses respiratory displacement variation as a function of consonantal characteristics, loudness, and prosodic focus in several speakers.

\subsection{Syllables, stress, and segments}

Early reports of short-term excursions (or "pulses") in respiratory system data came from Stetson (1951, originally published in 1928), who carried out a range of studies exploring respiratory control for speech. He collected various signal types, including electromyography (EMG), torso wall movements, and subglottal and esophageal pressures. Stetson proposed that individual syllables were associated with a "chest pulse" generated by the internal intercostal muscles.

Subsequent studies (e.g., Ladefoged et al., 1958) challenged this chest pulse theory. To a greater extent than Stetson, Ladefoged and colleagues employed EMG methods along with measures of chest wall movements and esophageal pressures. These authors argued that the internal intercostals did not show ballistic activity for individual syllables. They did, however, report increases in subglottal pressure for stressed syllables (Ladefoged, 1968), and presented one figure quantifying the frequency of single motor unit firing in the internal intercostals to argue that such activity increased before stressed syllables (Ladefoged et al., 1958). ${ }^{1}$ Ohala (1990) subsequently summarized counterevidence to the claim that stressed syllables are associated with greater respiratory system activity, and suggested that lung volume changes correlate with syllables that have emphatic rather than lexical stress.

Ladefoged (1968) made an additional observation that has received considerably less attention, namely, subglottal pressure could show short-term decreases during

\footnotetext{
a) Author to whom correspondence should be addressed.

b) Also at: Haskins Laboratories, New Haven, Connecticut 06511, USA.
} 
voiceless consonants. Ohala (1990) also acknowledged an interaction between the respi- 50 ratory and oral systems and reported having observed rapid changes in lung volume during regions of high airflow for consonants.

Despite these suggestions in the literature, there has been little subsequent consideration of the interaction between specific segmental and prosodic properties and their effect on respiratory kinematics. To the extent that previous authors have explored this possibility, the data presentation has been anecdotal and qualitative, in that the authors did not consistently quantify respiratory changes as a function of consonant type. Moreover, the number of speakers investigated in this work, although not consistently documented, was likely quite limited.

In a recent study (Petrone et al., 2017) we observed a regular rapid drop in respiratory volume after oral release (burst) in voiceless alveolar stops produced by women. However, that study did not compare voiceless stops to segments with a closed glottis in similar contextual and prosodic environments. From a purely logical perspective, it would make sense for segmentally-induced loss of air to affect respiratory system volumes. On the other hand, respiratory system volumes are quite large in comparison to whatever quantity of air might be released during an individual consonant such as an aspirated stop, particularly when one considers speakers with smaller glottal apertures (viz., women and children, who have smaller laryngeal structures than the men who were mainly represented in the early work). Thus, this study represents a systematic exploration of whether multiple speakers, mostly adult females, consistently show segmental effects on respiratory system displacements. In particular, we evaluate respiratory volume during consonants varying in glottal and velar opening (nasal stops, voiced oral stops, voiceless aspirated oral stops). Along with consonant type, we also consider possible interactions with prosodic changes at sentence and word levels via loudness (first experiment) and focus (second experiment) manipulations. Prosodic variation is of interest given that prosody can be manifested in articulatory changes at a segmental level. For German speakers, a larger glottal opening for voiceless stops has been observed in the production of loud in comparison to normal speech (Fuchs et al., 2004) and for focused in comparison to an unfocused position (Hoole and Bombien, 2017). It is not known, however, whether such prosodic effects on consonantal characteristics are reflected in respiratory patterns.

\subsection{Hypotheses}

We hypothesize that respiratory volume changes reflect laryngeal-oral coordination. Specifically, we expect that the slope of the respiratory volume declines more steeply at the release of voiceless aspirated stops than at the release of voiced and nasal stops. The steeper decline in voiceless stops should result from an open vocal tract after oral release which is coordinated with maximal glottal aperture. In voiced stops, phonetically realized as voiceless unaspirated or voiced word-initially in German, the glottis should be (almost) closed and less air can escape than with an open glottis, so that the slope of respiratory volume should not change to the same extent. Similarly, phonation in nasal stops should limit air loss and have only a marginal effect on respiratory volume changes.

We also expect effects to be larger in loud speech (experiment 1) and focused position (experiment 2) than in normal speech and unfocused position, because the degree of glottal opening for voiceless aspirated stops is larger in loud speech and under focus. Finally, we suppose that thoracic volume changes may be affected by loudness and focus, because the thorax is close to the larynx and the upper vocal tract and it has been discussed with respect to local respiratory changes (Ladefoged and Loeb, 2002). We do not expect consistent abdominal volume changes, since the abdomen is anatomically more distant from the larynx and upper vocal tract, and we generally associate it with slower motions (Thomasson and Sundberg, 2001).

\section{Experiment 1}

Participants were 11 native speakers of German (all female) with an age between 20103 and $37 \mathrm{yr}$ and a body mass index between 18 and 23. All were recorded in a seated 104 position. Thoracic and abdominal displacements (obtained using Inductive 105 Plethysmography) were recorded simultaneously with speech acoustics (Sennheiser 106 AQ4 microphone HKH50 P48) using a multi-channel system that prevented the need for 107 post-synchronization. The data were recorded with Edwin, software provided by the 108 manufacturer. The data were then converted to MATLAB (version 2017b) for analysis. 109

The speech material consisted of bisyllabic target words containing initial $/ \mathrm{m} \mathrm{b} \mathrm{p/,} 110$ a medial alveolar obstruent, and various vowels. Word with initial $/ \mathrm{m} /$ were: "Mieten" 111 
(rents), "Mitte" (section of Berlin), "Mate" (a tea), "Mützen" (caps), "München" 112 (Munich). Words with /b/ were "Butter" (butter), "Büsten" (busts), "Büsum" (an island) 113 and, with /p/, "Paddeln" (to canoe), "Pudel" (poodle), "Pita" (pita), "Pizza" (pizza), 114 "Paten" (god-parents), "Pasta" (pasta), "Pute" (turkey), "Pudding" (pudding). Thus, pho- 115 netically, the vowels following $/ \mathrm{m} /, / \mathrm{b} /$, and $/ \mathrm{p} /$ were, respectively, /i I y a:/, /v y/, and /i I 116 u $\cup$ a: a/, where /a:/ represents the tense vowel and /a/ is the lax counterpart, but both dif- 117 fer frequently only in vowel quantity.

The respective target words occurred sentence-initially. A question-answer 119 paradigm was employed. For example, the experimenter asked the question: "Magst 120 du X?" Do you like X? and the participant answered: "X mag ich, aber nicht Y." X I 121 like, but not $Y$. The participants supplied $\mathrm{Y}$. The inclusion of $\mathrm{Y}$ made the experiment 122 more engaging for participants, because they could partially create their own 123 responses. Speakers produced utterances in normal and loud conditions. Louder speech 124 was elicited by increasing speaker-experimenter distance.

Segments were labeled acoustically. For $/ \mathrm{m} /$ the onset was defined as the 126 beginning of vocal fold oscillation. The offset was determined as the beginning of 127 prominent formant structure corresponding to the beginning of the following vowel. 128 For the oral stops the onset was defined as the first visible burst and the offset as the 129 beginning of vocal fold oscillations for the following vowel. The slopes of thoracic and 130 abdominal volume changes were calculated from the acoustically annotated onset (x1) 131 to the offset (x2) of the segment (see Fig. 1 lower plots). Figure 1 shows the experimen- 132 tal setup and the annotation of the acoustic signals.

Thoracic and abdominal slopes were calculated using formula (1) where x 134 denotes the on- and offset of the segment (see Fig. 1) and y1 and y2 are the respiratory 135 signals obtained at times $\mathrm{x} 1$ and $\mathrm{x} 2$ from either the rib cage or the abdomen.

$$
\text { Slope }=(\mathrm{y} 2-\mathrm{y} 1) /(\mathrm{x} 2-\mathrm{x} 1) .
$$

The units for the respiratory data are arbitrary, but are consistent within each 137 speaker. $^{2}$

\subsection{Results}

Linear mixed effect models [version R 3.4.3, R Core Team, 2018), lme4 (Bates et al., 140 2015), lmerTest (Kuznetsova et al., 2017) were run with thoracic slope or abdominal 141 slope as the dependent variable, loudness, phoneme, and their interaction as indepen- 142 dent factors and speaker-specific slopes for loudness and phoneme. The reference level 143 was set to $/ \mathrm{p} /$ and normal speech. For pairwise comparisons involving other levels than 144 $/ \mathrm{p} /(/ \mathrm{b} / \mathrm{vs} / \mathrm{m} /)$, the reference level was changed and only $p$-values smaller than 0.025145 $[p=0.05$ divided by the number of models (2) run] were treated as significant. 146 Thoracic slope for $/ \mathrm{p} /$ was significantly steeper than in $/ \mathrm{m} /[\beta=-0.316$, standard error 147
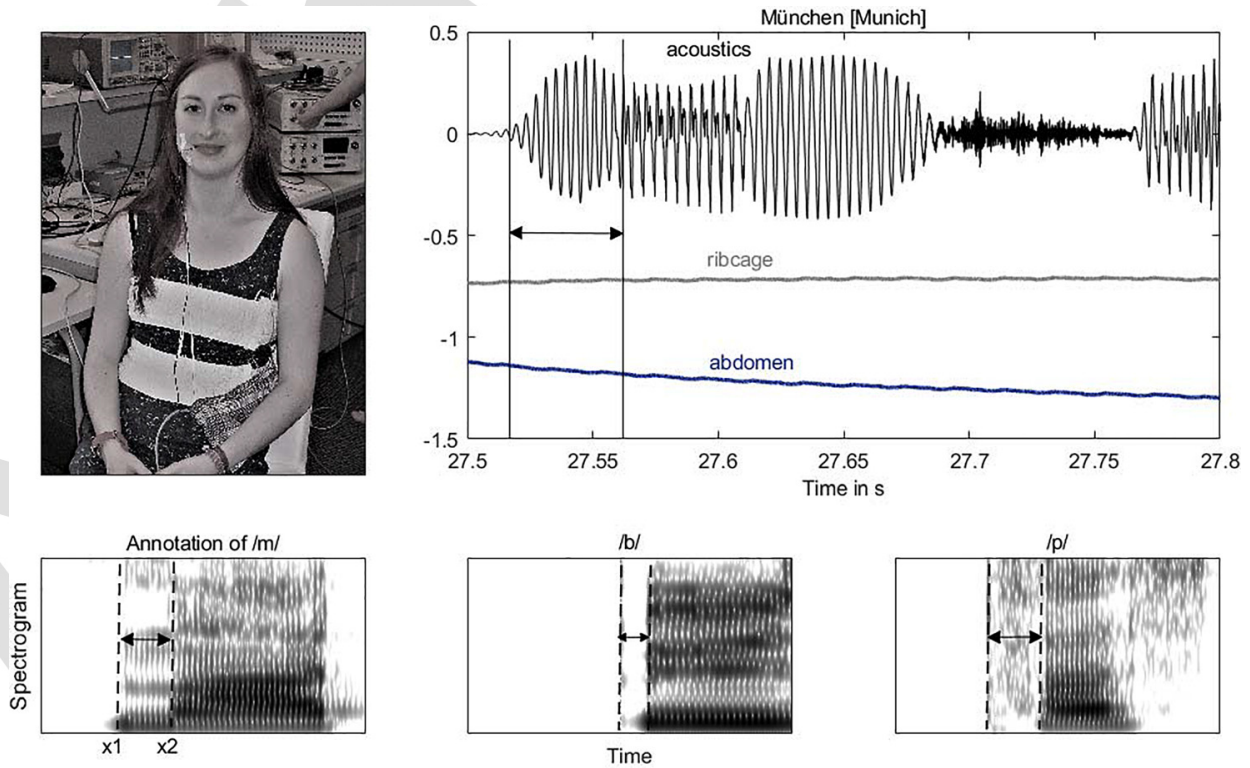

Fig. 1. (Color online) The upper plots show the experimental setup (participant sitting on a chair wearing the two respiratory belts) and the corresponding signals [acoustics (black line), thoracic volume changes (gray line), and abdominal volume changes (dark gray line below the ribcage signal) in arbitrary units]. The graphs below show the acoustic annotation which served as the input for obtaining the respiratory data during these regions. 


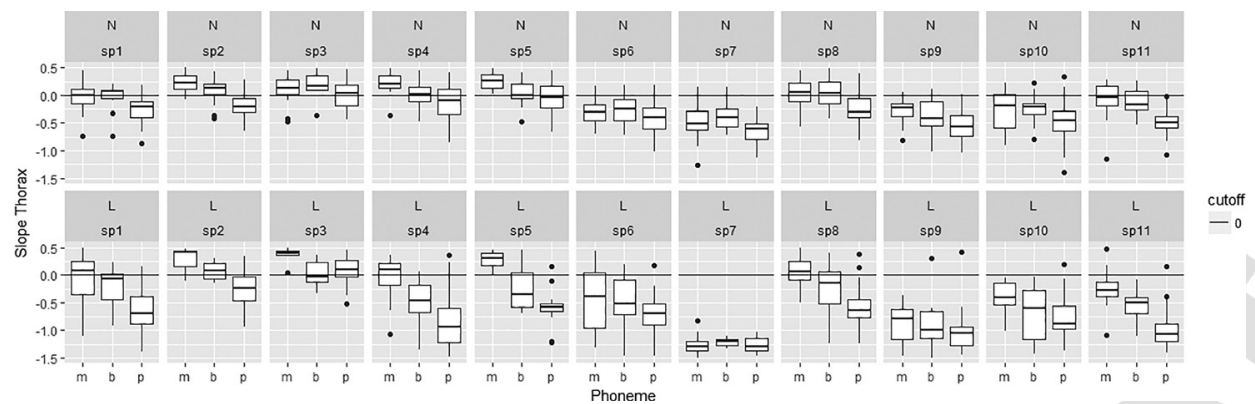

Fig. 2. Slope of the thoracic volume between the acoustically annotated on- and offsets ( $y$-axis) split by phoneme ( $x$ axis) and loudness (upper panels: normal, lower panels: loud). Individual speakers' results (spl-sp11) are displayed in the subplots. The horizontal line depicts a threshold. All values below this line refer to a decrease in thoracic volume (negative slope) while values above correspond to an increase in thoracic volume (positive slope). ${ }^{3}$ The number of all samples $(n)$ is 1705 .

AQ5 $\quad(\mathrm{SE})=0.051, t=-6.16, \quad p<0.001]$ and also steeper in $/ \mathrm{p} /$ than $/ \mathrm{b} /(\beta=-0.24,148$ $\mathrm{SE}=0.055, t=-4.4, p<0.001$ ) (see Fig. 2). No significant differences were found 149 between $/ \mathrm{b} /$ and $/ \mathrm{m} /$.

Loudness also revealed an effect with steeper slopes for loud speech than nor- 151 $\mathrm{mal}$ in $/ \mathrm{p} /(\beta=-0.49, \mathrm{SE}=0.195, t=-2.49, p=0.021)$, but no significant differences 152 in loudness were found for $/ \mathrm{b} /$ and $/ \mathrm{m} /$.

The abdominal slope revealed a difference between $/ \mathrm{p} /$ and $/ \mathrm{b} /$ with a shal- 154 lower (less negative) slope for $/ \mathrm{b} /(\beta=0.359, \mathrm{SE}=0.122, t=2.95, p=0.005)$, and a 155 shallower slope in $/ \mathrm{b} /$ than $/ \mathrm{m} /(\beta=0.391$, SE $=0.128, t=3.05, p=0.003)$. No differ- 156 ences between $/ \mathrm{p} /$ and $/ \mathrm{m} /$ were found and there was no effect of loudness.

\section{Experiment 2}

\subsection{Methodology}

Seven women and three men, all native speakers of German, were recorded. Respiratory 160 equipment and data annotation were the same as in experiment 1. Speakers had an age 161 between 22 and $36 \mathrm{yr}$ and body mass index between 19 and 25 (see Petrone et al., 162 2017). The speech material consisted of sentences with contrastive focus, i.e., a word in 163 a target utterance was contrasted with another word in the preceding context. The target 164 sentences were elicited using a question-answer paradigm. The experimenter asked a 165 question and the participant read the answer from a sheet of paper. Focused words 166 were written in capital letters. For example, the question "Wäscht er Tiegel"? (Does he 167 wash cups?) was used to prompt contrastive focus in the target utterance "Er NIMMT 168 Tiegel, aber wäscht sie nicht" (He TAKES cups, but does not wash them). Prompts that 169 put the final noun (e.g., "Tiegel") in focus yielded the no-focus condition for the verbs. 170 For analysis, we selected three verbs starting with a nasal or oral stop, i.e. $/ \mathrm{n} /$ in 171 "nimmt" (takes), /m/ in "malt" (paints), and /k/ in "kennt" (knows); the vowels in the 172 three words were /I a: $\varepsilon /$, respectively. Note that the current analysis differs from the 173 original study because here we assess the initial consonant of the verb whereas Petrone 174 et al. (2017) investigated the /t/ at the end of the verb.

\subsection{Results}

Two linear mixed-effects models (using the packages lme4, ImerTest) were run with 177 thoracic slope or abdominal slope as the dependent variable and focus, phoneme, and 178 their interaction as independent factors. The random structure included speaker specific 179 slopes for focus and phoneme. The voiceless stop / $/ \mathrm{k} /$ in the focus condition served as 180 the reference level and it was changed when comparing other phoneme pairs.

Statistical results showed that the thoracic slope was significantly shallower in 182 $/ \mathrm{n} /$ than $/ \mathrm{k} /(\beta=0.36, \mathrm{SE}=0.043, t=8.35, p<0.001)$, shallower for $/ \mathrm{m} /$ than $/ \mathrm{k} / 183$ $(\beta=0.34, \mathrm{SE}=0.043, t=8.02, p<0.001)$, and did not differ between $/ \mathrm{n} / \mathrm{and} / \mathrm{m} /($ see 184 Fig. 3). Thoracic slope was affected by focus in $/ \mathrm{k} /$, with a shallower slope for the no 185 focus than for the focus condition $(\beta=0.14, \mathrm{SE}=0.041, t=3.36, p=0.0016)$. Focus 186 did not affect thoracic slope in $/ \mathrm{m} /$ and $/ \mathrm{n} /$, and individual variation is evident (Fig. 3). 187

Results revealed no effect of focus on abdominal slope, but an effect of pho- 188 neme with a shallower slope for $/ \mathrm{n} /$ than $/ \mathrm{k} / \quad(\beta=0.176, \mathrm{SE}=0.062, t=2.85,189$ $p=0.0078$ ), but not for $/ \mathrm{k} /$ versus $/ \mathrm{m} /$. There were no differences between $/ \mathrm{n} /$ and $/ \mathrm{m} / . \quad 190$ 


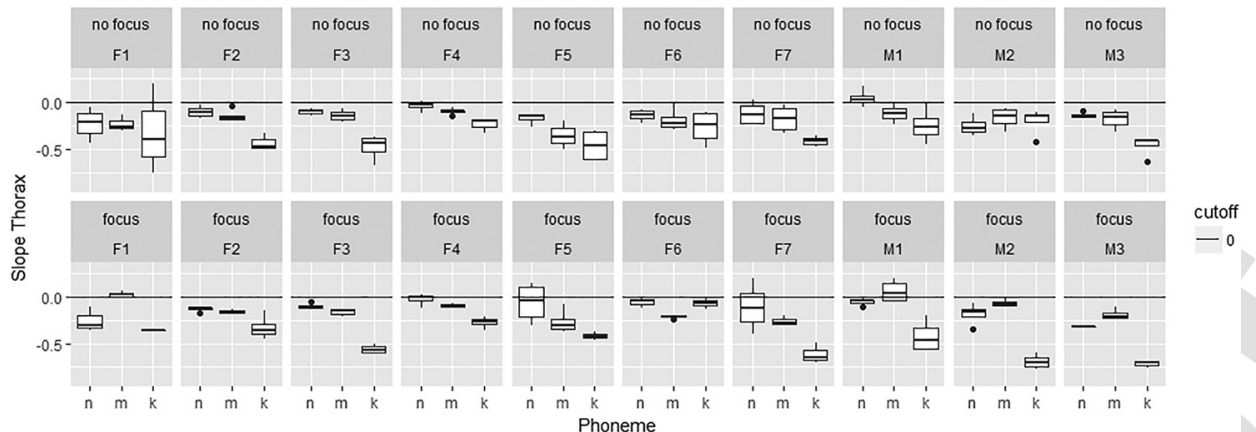

Fig. 3. Slope of the thoracic volume between the acoustically annotated on- and offsets ( $y$-axis) split by consonant ( $x$ axis) and focus (upper track: no focus, lower track: focus). Individual speakers' results are displayed in the subplots (seven females, three males). All values below the black horizontal line at zero indicate a decrease in thoracic volume (negative slope) while values above correspond to an increase in thoracic volume (positive slope). The number of all samples $(n)$ is 221 .

\section{Discussion and conclusion}

Results for two experiments with different participants revealed consistent local effects 192 on thoracic volume in voiceless aspirated consonants, which differ from voiced stops 193 and nasals in their laryngeal-oral coordination. Specifically, a larger amount of air can 194 escape when the vocal tract and the glottis are open in comparison to configurations 195 where the glottis is closed or the vocal folds vibrate. Patterns for voiceless stops were 196 rather consistent across speakers, with only a few speakers differing from the overall 197 pattern (Fig. 2: sp7, loud condition; Fig. 3, M2 and F6). A review of the acoustic data 198 for these few unusual speakers did not immediately show a reason for their atypical 199 behaviour.

We also obtained evidence for prosodic effects (loudness, focus) in the slope of 201 the thorax, but not the abdomen, in the vicinity of voiceless aspirated stops. The tho- 202 rax is closer to the larynx and thoracic muscles may also be more flexible and adapt- 203 able to short temporal changes in comparison to the global abdominal motions (e.g., 204 Ladefoged et al., 1958). It may also be that abdominal movements reflect greater iner- 205 tia than those of the thorax (cf. Thomasson and Sundberg, 2001). However, we note 206 that kinematic data do not necessarily allow firm conclusions about underlying physio- 207 logical processes. In our study the results could reflect an active involvement of the 208 thorax muscles, mechanical properties of the thorax and abdomen, or simply a larger 209 glottal aperture. A study adding measures of vocal-fold abduction or subglottal pres- 210 sure could help disentangle the possibilities here.

Our results also demonstrate that prosody affects the degree to which differ- 212 ences in consonantal aerodynamics are reflected in respiratory data. The effects are not 213 restricted to specific conditions, but are more extreme in loud speech and in words 214 under focus. This is in line with literature on prosodic strengthening and in particular 215 on laryngeal kinematics, where a larger glottal opening has been reported for strong 216 prosodic conditions than in weak ones (Fuchs et al., 2004; Hoole and Bombien, 2017). 217

Finally, we suggest that the short term negative excursions seen here may pro- 218 vide an alternative explanation for Stetson's chest pulses. That is, when one observes 219 an undulating signal, one might focus on the local increases (pulses) rather than the 220 local decreases ("valleys") as a phenomenon calling for explanation. Stetson's speech 221 material consisted to a large extent of CV syllables with $\mathrm{C}$ being voiceless stops; hence 222 it may not be surprising to find excursions on every syllable. Further, Stetson's experi- 223 mental design may have led to rather careful or staccato speech, i.e., the syllables 224 could also have received accentuation.

\section{Acknowledgments}

This work was supported by Grant No. 01UG1411 from the Ministry for Education and 227 Research (BMBF) and the Leibniz Society to S.F. at ZAS and by financial aid (Bonus 228 Qualité Recherche) from the Laboratoire Parole et Langage. We thank Jörg Dreyer for 229 technical support and our speakers for their participation. 
PROOF COPY [JASA-EL-00925] 506901JAS

Fuchs et al:: JASA Express Letters

${ }^{2}$ Since we did not merge thorax and abdomen kinematics to obtain overall lung volume, we cannot provide 236 the slope values in percent vital capacity.

${ }^{3}$ It is possible that some cases of positive slopes reflect preparatory chest wall positioning (cf. Hixon et al., 238 1988). However, we also obtained a few cases of positive slopes in experiment 2, where the analyzed words 239 were not in utterance-initial position.

Bates, D., Maechler, M., Bolker, B., and Walker, S. (2015). "Fitting linear mixed-effects models using 241 lme4," J. Stat. Software 67(1), 1-48.

Fuchs, S., Hoole, P., Pelorson, X., van Hirtum, A., Perrier, P., Dahlmeier, K., and Creutzburg, J. (2004). 244 "Laryngeal adjustment in voiceless consonant production: I. An experimental study of glottal abduction 245 in loud versus normal speech," in Proceedings of the Conference on Vocal Fold Physiology and 246 Biomechanics, Marseille, France, pp. 1-5.

Hixon, T. J., Watson, P. J., Harris, F. P., and Pearl, N. B. (1988). "Relative volume changes of the rib cage 248 and abdomen during prephonatory chest wall posturing," J. Voice 2(1), 13-19. 249

Hoole, P., and Bombien, L. (2017). "A cross-language study of laryngeal-oral coordination across varying 250 prosodic and syllable-structure conditions,” J. Speech Lang. Hear. Res. 60(3), 525-539. 251

Kuznetsova, A., Brockhoff, P. B., and Christensen, R. H. B. (2017). "ImerTest Package: Tests in linear 252 mixed effects models," J. Stat. Software 82(13), 1-26.

Ladefoged, P. (1968). "Linguistic aspects of respiratory phenomena," in Sound Production in Man, edited 254 by A. Bouhuys (New York Academy of Sciences, New York), pp. 141-151. 255

Ladefoged, P., and Loeb, G. (2002). "Preliminary studies on respiratory activity in speech," UCLA Work. 256

$\begin{array}{lll}\text { AQ8 Pap. Phon. 101, 50-60. } & 257 \\ \text { Ladefoged, P., and McKinney, N. (1963). "Loudness, sound pressure, and subglottal pressure in speech," } & 258\end{array}$

J. Acoust. Soc. Am. 35, 454-460. 259

Ladefoged, P., Draper, M. H., and Whitteridge, D. (1958). "Syllables and stress," Le Maître Phonétique 260 36, 1-14.

Leanderson, R., von Euler, C., and Sundberg, J. (1987). "Breathing muscle activity and subglottal pressure 262 dynamics in singing and speech," J. Voice 1, 258-262. 263

Ohala, J. J. (1990). "Respiratory activity in speech," in Speech Production and Speech Modelling, edited by 264

W. J. Hardcastle and A. Marchal (Kluwer, Dortrecht, The Netherlands), pp. 23-53. 265

Petrone, C., Fuchs, S., and Koenig, L. L. (2017). "Relations among subglottal pressure, breathing, and 266 acoustic parameters of sentence level prominence in German," J. Acoust. Soc. Am. 141, 1715-1725. 267

R Core Team (2018). "R: A language and environment for statistical computing," R Foundation for 268

$\begin{array}{lll}\text { AQ7 Statistical Computing, Vienna, Austria, URL http://www.R-project.org/. } & 269 \\ \text { Stetson, R. H. (1951). Motor Phonetics: A Study of Speech Movements in Action (North-Holland, 270 }\end{array}$

Amsterdam, the Netherlands), $212 \mathrm{pp.} \quad 271$

Thomasson, M., and Sundberg, J. (2001). "Consistency of inhalatory breathing patterns in professional 272 operatic singers," J. Voice 15, 373-383. 